\title{
KNOWLEDGE REGARDING ASSESSMENT OF HIGH RISK NEONATES AMONG NURSES WORKING IN SELECTED HOSPITALS OF RUPANDEHI
}

\author{
Anuja Kachapati, ${ }^{1}$ Shristi Sharma ${ }^{2}$
}

\section{ABSTRACT}

\section{INTRODUCTION}

There is need of early assessment and high quality nursing care for high risk neonates to reduce morbidity and mortality. Knowledge assessment is the pivotal step in assessing the status of patients' care given by the nurses. Researcher sought to assess level of knowledge regarding care of high risk neonates among nurses in selected hospitals in outreach Nepal.

\section{MATERIAL \& METHODS}

A descriptive cross-sectional study was conducted to find out the knowledge regarding assessment of high risk neonates among fifty five nurses selected through non probability enumerative method. The data was collected by using selfadministered semi-structured knowledge questionnaire and was analyzed by using descriptive and inferential statistics with SPSS software version 16.

\section{RESULTS}

The findings of the study revealed that more than half (58.18\%) of the nurses had high level of knowledge regarding assessment of high risk neonates.

\section{CONCLUSION}

Based on the study findings, it is concluded that more than half of the respondents in the study had high level of knowledge regarding assessment of high risk neonates. Beside this, the respondents have good knowledge pertaining to predisposing factors, diagnostic tools, initial clinical assessment, preventive measures, management of high risk neonates and definition of preterm, post-term, low birth weight neonates. Respondents had low level of knowledge for clinical characteristics of small for gestational age neonates as well as clinical parameters of high risk neonates. Hence, there is utmost need to give in-service education to the nurses in order to achieve the quest to improve their knowledge relating to care of high risk neonates.

KEYWORDS Assessment of high risk neonates, knowledge, nurses

1. Universal College of Nursing Sciences, Bhairahawa, Nepal

2. Sanjeevani College of Medical Sciences, Butwal, Nepal

DOI: https://doi.org/10.3126/jucms.v6i2.22496

\author{
For Correspondence \\ Ms. Anuja Kachapati \\ Universal College of Nursing Sciences \\ Bhairahawa, Nepal \\ Email:anuja_kakshapati@yahoo.com
}




\section{INTRODUCTION}

The high risk neonates can be defined as any neonates who have high risks of impending serious illness or death as a result of any perinatal adverse circumstances ${ }^{1}$ which includes birth weight less than 1800 gm or gestational age less than 34 weeks, delayed passage of meconium and urine, inability to suck and swallow, reduced activity and excessive crying, marked changes in skin color, cold baby or febrile baby, rapid breathing more than 60 breaths per minute, chest retractions, superficial infections with purulent conjunctivitis, oral thrush, umbilical sepsis, pyoderma, abscess, persistent vomiting, watery diarrhea, abdominal distension, bleeding from any site and any features of injury, convulsions and abnormal movements, delayed capillary refill time or sudden loss of weight. $^{2}$

Each year about 32.4 million of children are born with low birth weight, which is below the 10th percentile for their gestational ages; moreover, about fifteen million of them are premature. Actually, about $60 \%$ of neonatal deaths occur in low birth weight neonates related to their prematurity.

In Nepal, the prevalence of pre-term birth is estimated about $14-30 \%$ and low birth weight is 12 to $32 \%$. According to Nepal Demographic Health Survey (NDHS) 2016, 21 neonatal deaths per 1000 live birth is accountable owing to infection, birth asphyxia, preterm birth and hypothermia. ${ }^{5}$ The survey conducted in tertiary hospital of Nepal showed that about $14 \%$ of babies were born preterm and $39.3 \%$ were small for gestational age (SGA) babies in 2010. There was 12 fold increase risk of neonatal death among preterm babies. Babies who were SGA had $40 \%$ higher risk of neonatal death. Additionally, babies who were both preterm and SGA were 16 times more likely to die during the neonatal period. ${ }^{6}$

Nurses are among the primary managers in early identification and optimal care of high risk fetuses and neonates and thereby play pivotal role in all in minimizing deaths associated with same. Threats to wellness and indeed life can occur at anytime of perinatal period from that of the viability of the fetus to 28 days after birth. ${ }^{7}$ The main objectives of the study were to find out the level of knowledge regarding assessment of highrisk neonates among nurses and the association between level of knowledge regarding assessment of high-risk neonates and selected demographic variable

\section{MATERIAL AND METHODS}

A descriptive cross-sectional design was adopted to assess the knowledge regarding assessment of high risk neonates among nurses. The study was conducted in Neonatal Intensive Care Unit (NICU), pediatric, postnatal and labor wards of
Universal College of Medical Sciences, Teaching Hospital (UCMS-TH), Siddharthanagar-1, Rupandehi and in Siddhartha Children and Women hospital (SCWH), Butwal-7, Rupandehi. 55 nurses (29 from UCMS-TH and 26 from $\mathrm{SCWH}$ ) were selected in the study sample through non probability enumerative method.

Self-administered pretested semi-structured knowledge questionnaire was developed by researchers reviewing the related literatures and consulting with the subject experts. There were altogether twenty questions formed relating to assessment of high risk neonates.

The researchers reached every ward and obtained the written informed consent with each nurses for enrollment in this study with semi-structured knowledge questionnaire. Data collection was done after two weeks of formal assessment.

Administrative and ethical approval was obtained from the concerned authorities prior to data collection. Descriptive and inferential statistical method was used with SPSS version 16 to analyze the data.

The questionnaire consisted of two parts;Part I: related to socio-demographic variables and Part II: related to knowledge regarding assessment of high-risk neonates.

The study was conducted from $12^{\text {th }}$ February to $25^{\text {th }}$ April 2017. Pretest of the instrument was conducted on 6 respondents in Devdaha Medical College, Teaching Hospital, Devdaha-9, Nepal.The exclusion criteria were nurses not willing to participate and auxiliary nurse midwives working in intensive care units. All the collected data were analyzed by using descriptive statistics and inferential statistics with Statistical Package for Social Sciences (SPSS) software version 16.

\section{RESULTS}

Most (89.1\%) of the nurses had completed Proficiency Certificate Level in Nursing. Regarding current working department, $43.6 \%$ nurses were in pediatric ward and only $12.7 \%$ were in labor ward. Forty percentage of nurses had working experience of more than 3 years. None of the nurses had received training pertaining to care of high risk neonates.

With regards to knowledge regarding predisposing factors of high risk neonates, $80 \%$ of nurses correctly answered pregnancy between 15-19 years as the most common factor while only $1.8 \%$ of them cited proper birth spacing for the same. As per aspects of knowledge regarding initial assessment of high risk neonates, $89.1 \%$ of the nurses answered APGAR score as the initial assessment tool for high risk neonates. 
Table 1. Nurses' knowledge regarding predisposing factors and initial assessment of high risk neonates

\begin{tabular}{|l|c|c|}
\hline Variables & $\begin{array}{c}\text { Frequency } \\
(\mathbf{n}=55)\end{array}$ & Percentage \\
\hline Predisposing factors** & 44 & 80.0 \\
Pregnancy between 15-19 years* & 44 & 70.9 \\
Elderly pregnancy above 35 years* & 39 & - \\
Term gestation & - & 50.9 \\
Medical illness* & 28 & 1.8 \\
Proper birth spacing & 1 & 61.8 \\
Multiple pregnancy* & 34 & 63.6 \\
Abnormal pregnancy* & 35 & 61.8 \\
Low socio economic status* & 34 & \\
Initial Assessment & & 9.1 \\
Newborn examination & 5 & 89.1 \\
APGAR score* & 49 & - \\
Blood test & 1 & -8 \\
Urine Test & - & \\
\hline
\end{tabular}

**Multiple responses; *Correct response

Mean percentage score of predisposing factors of high risk neonates64.83

As per knowledge regarding preterm neonates, $61.8 \%$ of nurses labeled neonates born before 37 weeks of gestation for the same, while $1.8 \%$ of them answered neonates born after 32 weeks of gestation as the criteria for defining preterm neonates. Around $85 \%$ of nurses answered undescended testicles and $3.6 \%$ answered scanty vernix as the sign of a preterm male baby. $61.8 \%$ of nurses answered soft flat ears with little cartilage and $10.9 \%$ answered labia majora covering labia minora as the clinical characteristics of preterm neonates. Eighty percentage of the nurses answered neonates born after 42 weeks of gestation and 3.6\% answered neonates born at 40-42 weeks of gestation as the definition of post-term neonates. Most (78.2\%) of the nurses correctly answered birth weight less than 2500 as the low birth weight neonates. Regarding meaning of very low birth weight neonates, $58.2 \%$ of nurses answered birth weight less than 1500 gm. Pertaining to the meaning of extremely low birth weight neonates, $89.1 \%$ of respondents answered birth weight less than $1000 \mathrm{gm}$. More than half $(65.5 \%)$ of the nurses answered less than $10^{\text {th }}$ percentile of its gestational age as the meaning of small for gestational age neonates. Regarding characteristics of small for gestational age neonates, $76.4 \%$ of nurses answered old man look and $1.8 \%$ answered weight more than $2500 \mathrm{gm}$. Total of $60 \%$ of respondents answered hypothermia as the major complication among small for gestational age neonates. Near to half $(49.1 \%)$ of the nurses answered more than $90^{\text {th }}$ percentile of its gestational age as the meaning of large for gestational age neonates. Regarding diagnostic evaluation during pregnancy for high risk neonates, $83.6 \%$ of the nurses opted for ultrasonography and $1.8 \%$ of them chose magnetic resonance imaging.
Regarding clinical features of high risk neonates, $81.8 \%$ answered poor reflexes whereas only $9.1 \%$ responded excess presence of vernixcaseosa for the same. Pertaining to the common problems of high risk neonates, $87.3 \%$ answered respiratory distress whereas $5.5 \%$ answered polycythemia and anemia. Majority $(92.7 \%)$ of the nurses responded to regular antenatal checkup whereas $81.8 \%$ identified intake of nutritious diet as the preventive measures for high risk neonates.

Table 2. Nurses' knowledge regarding clinical features, common problems and prevention of high risk neonates

\begin{tabular}{lcr}
\hline Variables & Frequency $(\mathbf{n}=\mathbf{5 5})$ & Percentage \\
\hline Clinical Features** & & \\
Labia majora covering labia minora & 9 & 16.4 \\
Soft flat ears with little cartilage* & 19 & 34.5 \\
Wrinkled and loose skin* & 28 & 50.9 \\
Poor reflexes* & 45 & 81.8 \\
Excess presence of vernixcaseosa* & 5 & 9.1 \\
Presence of edema around eyes, face & & \\
and scrotum & 19 & 34.5 \\
Fragile skin* & 31 & 56.4 \\
Little subcutaneous fat* & 23 & 41.8 \\
Common problems** & & \\
Respiratory distress* & 48 & 87.3 \\
Hypothermia* & 34 & 61.8 \\
Polycythemia & 3 & 5.5 \\
Feeding problems* & 38 & 69.1 \\
Neonatal sepsis* & 29 & 52.7 \\
Birth asphyxia* & 29 & 52.7 \\
Hypoglycemia* & 25 & 45.5 \\
Anemia & 3 & 5.5 \\
Prevention** & & \\
Intake of nutritious diet* & 45 & 7.3 \\
Heavy exercise & 4 & 9.5 \\
Avoid smoking and alcohol* & 41 & 9.1 \\
Regular antenatal checkup* & 51 & \\
Reducing weight & 5 & \\
\hline
\end{tabular}

**Multiple responses; ${ }^{*}$ Correct response

Mean percentage score of clinical feature of high risk neonates- 45.75 Mean percentage score of common problems of high risk neonates61.51

Mean score percentage of prevention of high risk neonates- 81.35

Regarding management of high risk neonates, $78.2 \%$ of nurses answered clearing the airway as the initial step whereas $78.2 \%$ responded with infection control and 3.6\% answered fluid restriction as the subsequent management options of high risk neonates.

Table 3. Nurses' knowledge regarding management of 


\section{high risk neonates}

\begin{tabular}{|c|c|c|}
\hline Variables & $\begin{array}{l}\text { Frequency } \\
\qquad(\mathrm{n}=55)\end{array}$ & Percentage \\
\hline \multicolumn{3}{|l|}{ Initial management } \\
\hline Umbilical cord care & - & - \\
\hline $\begin{array}{l}\text { Clear the airway* } \\
\text { Breast feeding }\end{array}$ & 43 & 78.1 \\
\hline Eye care & 10 & 18.4 \\
\hline Later management** & 2 & 3.5 \\
\hline Systemic assessment* & 32 & 58.2 \\
\hline Maintain warmth* & 39 & 70.9 \\
\hline Prevention from infection* & 43 & 78.2 \\
\hline Place in cross ventilated environment* & 27 & 49.1 \\
\hline Maintain feeding pattern* & 37 & 67.3 \\
\hline ** Fluid restriction & 2 & 3.6 \\
\hline
\end{tabular}

More than half (58.18\%) of the nurses had high level of knowledge regarding assessment of high risk neonates.

Table 4. Overall knowledge regarding assessment of high risk neonates

\begin{tabular}{ccc}
\hline Level of knowledge & $\begin{array}{c}\text { Frequency } \\
(\mathbf{n = 5 5})\end{array}$ & Percentage \\
\hline High & 32 & 58.18 \\
Average & - & - \\
Low & 23 & 41.82 \\
\hline
\end{tabular}

There was no significant association between work experience and nurses' level of knowledge regarding assessment of high risk neonates $(\mathrm{p}=0.990)$.

Table 5. Association between work experience and nurses' level of knowledge regarding assessment of high risk neonates

$$
\mathrm{n}=55
$$

\begin{tabular}{lllll}
\hline Work Experience & \multicolumn{2}{c}{ Level of Knowledge } & \multirow{2}{*}{$\chi^{2}$} & p- value \\
\cline { 2 - 3 } & gh & Low & & \\
\hline Less than 1 year & $7(58.3)$ & $5(41.67)$ & 0.00 & 0.990 \\
More than 1 years & $25(58.13)$ & $18(41.87)$ & & \\
\hline Significance level at 0.05 & & &
\end{tabular}

\section{DISCUSSION}

The findings of the study showed that $80 \%$ of the nurses had knowledge regarding pregnancy between ages 15 -19 years, $50.9 \%$ had knowledge regarding medical illness and $61.8 \%$ had knowledge regarding multiple pregnancy as predisposing factors of high risk neonates. The findings of the study is not consistent with the study of Levision et al (2014) conducted in
Malawi (Africa) which showed 64.3\% had knowledge regarding pregnancy between age $15-19$ years and $23.2 \%$ had knowledge regarding medical illness. The findings are consistent with the study of Levision et al (2014) which showed $65 \%$ of responders had knowledge regarding multiple pregnancy. $^{8}$

The findings of the study showed that $61.8 \%$ of the nurses had knowledge regarding low socio economic status as predisposing factors of high risk neonates which is consistent with the study by Amoula et al (2016) conducted in Sudan, Africa which showed $62 \%$ had knowledge regarding low socio economic status as predisposing factors of high risk neonates. ${ }^{9}$

The findings of the study showed that $61.8 \%$ of the nurses had knowledge regarding preterm neonates which is not consistent with the study of Hassan (2010) conducted in Gezira State, Sudan which showed $88.9 \%$ of them correctly defined preterm neonates. The findings of the study showed that $80 \%$ of the nurses had knowledge defining post-term neonates as those born after 42 weeks of gestation. ${ }^{10}$

The findings of the study showed that $78.2 \%$ of the nurses had knowledge regarding low birth weight neonates which is not consistent with the study of Ayiasiet al (2014) conducted in Masindi, Uganda, Africa which showed only $45.4 \%$ had accurate knowledge regarding low birth weight neonates.

The findings of the study showed that $65.5 \%$ of the nurses had knowledge regarding small for gestational age neonates. ${ }^{12}$ The findings of the study showed that $49.1 \%$ of the nurses had knowledge regarding large for gestational age neonates. The findings of the study showed that $78.2 \%$ of the nurses had good knowledge regarding history taking and $83.6 \%$ correctly opted for ultrasonography as the diagnostic evaluation to identify high risk neonates during pregnancy which is not consistent with the study of Levision et al (2014) conducted in Malawi, Africa which showed that $54.6 \%$ had good knowledge regarding history taking and $97 \%$ had knowledge regarding ultrasonography as the diagnostic tool in identifying high risk neonates during pregnancy. ${ }^{8}$

The findings of the study revealed that $89.1 \%$ of the nurses had knowledge regarding APGAR score as initial assessment tool in high risk neonates. The findings of the study showed that $34.5 \%$ of the nurses had knowledge regarding soft flat ears with little cartilage as the clinical marker of high risk neonates which is not consistent with the study of Hassan (2010) conducted in Gezira State, Sudan which showed $83 \%$ of respondents had knowledge regarding characteristics of premature infants. ${ }^{10}$ The findings of the study showed that $87.3 \%$ of the nurses had knowledge regarding respiratory 
distress and $61.8 \%$ had knowledge regarding hypothermia as common problems among high risk neonates which is not consistent with the study of Hassan (2010) conducted in Gezira State, Sudan which showed $86.7 \%$ had similar knowledge. ${ }^{10}$

The findings of the study showed that $78.2 \%$ of the respondents had adequate knowledge regarding initial management of high risk neonates which is not consistent with the study of Amoula et al (2016) conducted in Sudan, Africa which showed that almost $90 \%$ had the knowledge of clearing the airway by suctioning as the immediate management for high risk neonates. ${ }^{9}$ The findings of the study showed that $70.9 \%$ of the respondents had knowledge regarding maintaining warmth and $78.2 \%$ had knowledge regarding prevention from infection as the management algorithm of high risk neonates. The findings of our study is consistent with the study of Ayiasi et al (2014) conducted in Masindi, Uganda, Africa which showed $79.2 \%$ of the respondents had knowledge regarding keeping the child warm whereas the findings of our study is not consistent with the study of Ayiasi et al (2014) which reported $72.1 \%$ had knowledge regarding prevent from infection as the subsequent management strategy among high risk neonates. ${ }^{11}$

\section{CONCLUSION}

Based on the study findings, it is concluded that more than half of the nurses have high knowledge regarding assessment of high risk neonates. Nurses have high knowledge regarding predisposing factors, diagnostic tests, preventive measures, management of high risk neonates and meaning of preterm, post-term, low birth weight and small for gestational age neonates whereas nurses have low knowledge regarding characteristics of preterm neonates and small for gestational age neonates, meaning of large for gestational age neonates and clinical features of high risk neonates. There is no statistically significant association between duration of work and respondents' level of knowledge regarding assessment of high risk neonates. Therefore, there is need to provide inservice education to the nurses in order to improve their knowledge relating to assess and care of high risk neonates which help to decrease morbidity and mortality of neonates.

\section{ACKNOWLEDGEMENTS}

Researchers deeply express their heartfelt thanks to all women who participated in the study for immense support and cooperation. Researchers express their deep and sincere gratitude to all those experts for their valuable judgment, constructive feedbacks and enlightening suggestions throughout the study.

\section{REFERENCES}

1. Patrich L. High risk newborn [Internet] 2011. Available from: https://www.scribd.com/5416225/The_High_Risk_Newborn.

2. Pieron P. Identification of high risk neonates [Internat] 2012. Available from: www.austincc.edu/adnlev3/high risk_neonates.

3. Alsadi E. Comparison Study of Causes and Neonatal Mortality Rates of Newborns Admitted in Neonatal Intensive Care Unit of Al-Sadder Teaching Hospital in Al-Amara City, Iraq. International Journal of Pediatrics. 2017 Mar 1;5(3):4601-11.

4. Government of Nepal Population Division, Ministry of Health and Population. Nepal Demographic Health Survey [Internet] 2011. Available from: http://un.org.np/datacoll/Health publications /2016_NDHS-pre.pdf.

5. Ashish KC, Wrammert J, Nelin V, Ewald U, Clark R, Målqvist M. Level of mortality risk for babies born preterm or with a small weight for gestation in a tertiary hospital of Nepal. BMC public health. 2015 Dec;15(1):877.

6. Prasanna K. Assess the knowledge regarding assessment of high risk neonates among staff nurses and nursing students in selected hospitals at Nellore, AP. IJAR. 2016;2(6):730-4.

7. Phanase BN. Effectiveness of Structured Teaching Programme (STP) on knowledge regarding care of low birth weight babies among staff nurses working at hospitals of Vidarbha region. International Journal of Nursing Education and Research. 2016;4(2):95-8

8. Levison J, Nanthuru D, Chiudzu G, Kazembe PN, Phiri H, Ramin SM, Aagaard KM. Qualitative assessment of attitudes and knowledge on preterm birth in Malawi and within country framework of care. BMC pregnancy and childbirth. 2014 Dec; 14(1):123.

9. Amoula IW, Kambal EI. Pediatric nurse's knowledge and practices regarding nursing management of premature babies in neonatal intensive care unit. IntJof Recent Res in Life Sci [Internet] 2016; 3(4): 1-9. Available from:www.paper. publications. org\%20Nurses\%20knowledge_858\%20(4).pdf

10. Hassan AE. Effect of the Training Program on Nurses' Knowledge, Attitude and Practice regarding Neonatal Nursing Care in Obstetrics and Gynecology and Pediatric Teaching Hospitals at Wad Medani, Gezira State, Sudan (20102013)(Doctoral dissertation, University of Gezira).

11. Ayiasi RM, Criel B, Orach CG, Nabiwemba E, Kolsteren P. Primary healthcare worker knowledge related to prenatal and immediate newborn care: a cross sectional study in Masindi, Uganda. BMC health services research. 2014 Dec;14(1):65. 